\title{
Modeling Vaccination Programs in Outbreaks of Hemorrhagic Septicemia in India
}

\author{
Deepak $^{1 *}$, Dinesh Gulia ${ }^{2}$ and Sharif S. Aly ${ }^{3}$ \\ ${ }^{1}$ Department of Preventive Veterinary Medicine, University of California, Davis, CA, USA \\ ${ }^{2}$ Veterinary Surgeon, Department of Animal Husbandry \& Dairying, Haryana, INDIA \\ ${ }^{3}$ Department of Population Health and Reproduction, School of Veterinary Medicine, University of California - Davis, \\ Davis, CA, USA \\ "Corresponding author: Deepak; E-mail: deepakdhillonv17b@gmail.com
}

Received: 09 Jan., 2020

Revised: 14 Jan., 2020

Accepted: 25 Jan., 2020

\begin{abstract}
Hemorrhagic septicemia (HS) is an acute septicemic endemic disease of buffalo and cattle in India with a case fatality rate of up to $80 \%$. This disease causes an estimated economic loss of USD 792 million per year in India. Vaccination and control programs of HS can be understood by mathematical models. The main objective of our study was to design a mathematical model to analyze the effect of vaccination in controlling outbreaks of HS in India. We used posteriori model building approach to create and run the model for HS with the help of an outbreak data from Murshidabad district, West Bengal, India. The best possible transmission coefficient $(\beta)$ to imitate the outbreak was found to be 0.335 and the best possible basic reproduction number $\left(R_{0}\right)$ was found to be 1.011 . Introduction of the vaccination campaign from $5^{\text {th }}$ to the $20^{\text {th }}$ day of the HS outbreak reduced the proportion of the susceptible animals from 0.99 to 0.40 on the last day of the campaign. We concluded that animal vaccination modelling for eradication of HS by mass regional or nationwide vaccination campaigns can be understood by simple mathematical models.
\end{abstract}

Keywords: Hemorrhagic septicemia, Transmissible Coefficient, Reproductive Number, Outbreak, Vaccination

Hemorrhagic septicemia (HS) is an immensely deadly septicemic disease of acute nature in buffalo and cattle (Shome et al., 2019). HS is prevalent in almost every part of India (Singh et al., 2014). This disease is caused by Pasteurella multocida which is a gram-negative coccobacillary commensal bacteria in the upper respiratory tract of animals (Kumar et al., 1996). Pasteurella multocida serotype B:2 (Asian serotype) and serotype E:2 (African serotype) are mainly responsible for HS in India (Kumar et al., 1996). Clinical signs of HS include fever, nasal discharge, respiratory distress, frothy salivation, and recumbency and death in advanced stages (Abusalab, 2003; Shah et al., 2006). Buffaloes are more susceptible to HS as compared to the cattle and younger animals are more susceptible to HS as compared to the older animals (Singh et al., 2014).

During 1974-1986, HS caused maximum mortalities in buffaloes and cattle among all infectious diseases in India (Dutta et al., 1990). HS is the second most reported disease in buffaloes and cattle during 1991 to 2010 in India (Singh et al., 2014). The case fatality rate in HS outbreaks may go up to $80 \%$ (Farooq et al., 2011). Out of all the HS outbreaks in India, 97\% are observed in the larger ruminants (Gajendragad and Uma, 2012). Due to a huge number of buffaloes and cattle in India, HS has come forth as a disease of substantial economic importance with an estimated economic loss of USD 792 million per year in India (Singh et al., 2014). HS outbreaks occur in India every year even after the availability of multiple vaccine formulations for this disease. Although implementation of vaccination campaigns during a HS outbreak is not

How to cite this article: Deepak, Gulia, D. and Aly, S.S. (2020). Modeling Vaccination programs in outbreaks of hemorrhagic septicemia in India. J. Anim. Res., 10(1): 19-24. 
sufficient to stop the very high morbidity and mortality (ICAR-NIVEDI, 2018) but it can be an important tool in curtailing them to a great extent. Pinpointing the endemic areas of HS and implementing obligatory vaccination in these areas can be helpful in preventing future HS outbreaks (ICAR-NIVEDI, 2018). In India, outbreaks of HS mainly occur during rainy season specifically in early monsoon from July to September. Vaccination against HS is the only handy tool for prevention as well as for the control of the disease. Use of improper and less potent vaccines can be of no use for stopping the disease (Gowrakkal et al., 2014).

Mathematical models of outbreaks are helpful in understanding the impact of vaccination programs from a long time. Target vaccination coverage for eradicating a disease can be understood by simpler oneline models but for other complex questions, complex stochastic mathematical models are required (Schrer and McLean, 2002). The epidemiology of HS and its vaccine characteristics such as proportion of initially vaccinated animals, the duration of protection by the vaccine and the total animal population covered by the vaccination program are important things to understand to model the vaccination programs of HS during an outbreak (Woolhouse et al., 1997). Hence, the main objective of our study was to design a mathematical model to check the effect of regular HS vaccination programs in the large ruminant populations for prevention of HS outbreaks in India. We also focused on the calculation of basic reproduction number $\left(R_{0}\right)$ for HS on the basis of the data available for various outbreaks in Kazakhstan in May, 2016 ("Promed Post - ProMED-mail," n.d.), in Israel in March, 2017 ("PRO/AH> Hemorrhagic septicemia - Israel: (HZ) bovine, OIE Outbreak Watch," n.d.), in Malaysia from $29^{\text {th }}$ September to $10^{\text {th }}$ October, 2003 (Bisht et al., 2004) and in Haryana state of India from 1995 to 1999 (Jindal et al., 2002). We also aimed to examine the influence of the introduction of a vaccination campaign on the characteristics of a HS outbreak.

\section{MATERIAL AND METHODS}

To reduce the number of new infectious cases and hence, to decline the overall morbidity of the disease, each infectious case should generate less than one new infectious case. The total number of secondary infectious cases generated by one infectious case is called as the effective reproductive number $(R)$. Outbreaks start declining when the $R$ drops below one due to the temporary exhaustion of the susceptible population. The total number of secondary cases generated by one primary case introduced into a fully susceptible population is called as the basic reproductive number $\left(R_{0}\right)$. The total number of secondary cases generated by one primary case introduced into a population in which a proportion $p$ has been vaccinated is called as the basic reproductive number under vaccination $\left(R_{O_{v}}\right) . R_{O_{v}}$ for a vaccine which provides lifelong immunity $=\left[(1-p) R_{0}\right]$. For eradication of a disease from the population $R_{0}$ should be at least one or less than that. Therefore, the critical vaccination proportion $\left(p_{c}\right)$ to eradicate a disease from the population $=\left(1-1 / R_{0}\right)($ Schrer and McLean, 2002).

Mathematical models are useful in predicting the dynamics of the disease outbreak with or without the introduction of a vaccination program during the outbreak. A population with a vaccination program contains four different group of animals: susceptible $(S)$, vaccinated $(V)$, infected $(I)$, and recovered $(R)$. The immunity of commercially available and commonly used alum-precipitated HS vaccines is from 4 to 6 months and that for the oil-adjuvant HS vaccines is up to 1 year (Verma and Jaiswal, 1998). Since, the duration of a HS outbreak is generally less than the immunity time period of any HS vaccine, the equations of our SVIR model are (Fig. 1):-

$$
d S / d t=(1-e p) \mu N-\beta I S-\mu S
$$

Where $N$ is the total animal population $(S+V+I+R),(1-$ ep) $\mu N$ are the unvaccinated births, $\beta I S$ are the infected animals, and $\mu S$ are the deaths in susceptible.

$$
d V / d t=e p \mu-\mu V
$$

Where $е p \mu N$ are the vaccinated births, and $\mu V$ are the deaths in vaccinated.

$$
d I / d t=\beta I S-\gamma I-\mu I
$$

Where $\beta I S$ are the infected animals, $\gamma I$ are the recovered animals, and $\mu I$ are the deaths in the infected.

$$
d R / d t=\gamma I-\mu R
$$

Where $\gamma I$ are the recovered animals, and $\mu R$ are the deaths in the recovered. 


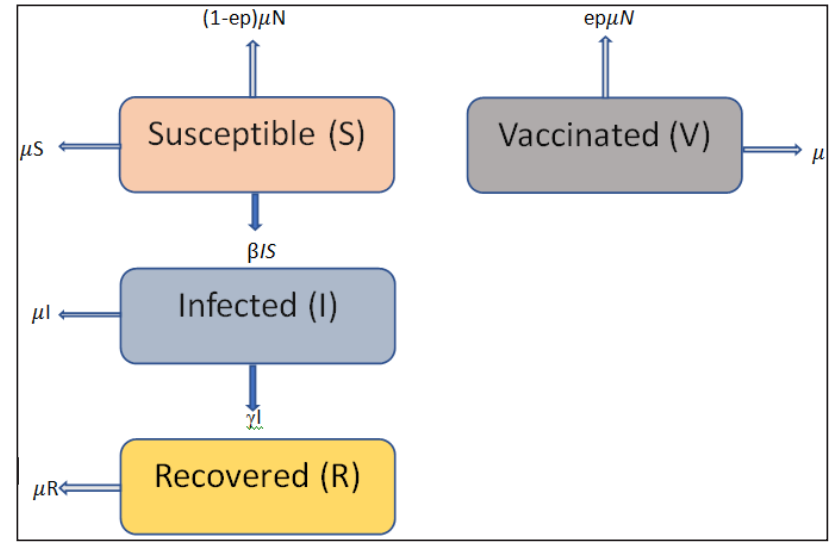

Fig. 1: Different groups of animals in the animal population during vaccination: susceptible $(S)$, vaccinated $(V)$, infected $(I)$, and recovered $(R)$. The arrows in the figure show the entry or exit of animals in various afore-mentioned animal groups

The model parameters used in the above transitions' equations are calculated from a HS outbreak data from Murshidabad district, West Bengal, India (Mitra et al., 2013). The population at risk is assumed to be fixed where birth rate is equal to the death rate. The model parameters are described below in Table 1.

Table 1: Numerical values and interpretations of model parameters

\begin{tabular}{|c|c|c|}
\hline Parameter & $\begin{array}{l}\text { Numerical } \\
\text { value }\end{array}$ & Interpretation \\
\hline$\overline{\mathrm{R}_{0}}$ & 1.011 & $\begin{array}{l}R_{0}=-\operatorname{Ln}(1-I) / I \text { where } I=0.0216 \text { is } \\
\text { the proportion infected at the end of } \\
\text { the outbreak (Dietz, 1993) }\end{array}$ \\
\hline $\begin{array}{l}N \text { (Population } \\
\text { size) }\end{array}$ & 7120 & $S+V+I+R$ \\
\hline $\begin{array}{l}\beta \\
\text { (Transmission } \\
\text { force) }\end{array}$ & 0.335 / day & $\begin{array}{l}\beta=R_{0}^{*} \gamma(\text { Kermack and } \\
\text { McKendrick, 1927) }\end{array}$ \\
\hline$L$ (Lifespan) & 30 years & Average lifespan (Cockrill, 1977) \\
\hline$\mu$ (Death rate) & $12.16 /$ day & $\mu=1 / L$ \\
\hline $\begin{array}{l}D \text { (Duration of } \\
\text { infection) }\end{array}$ & 3 days & $\begin{array}{l}D=24 \text { hours to } 5 \text { days (Average } 3 \\
\text { days) }\end{array}$ \\
\hline $\begin{array}{l}\gamma(\text { Recovery } \\
\text { rate })\end{array}$ & 0.33 / day & $\gamma=1 / D$ \\
\hline $\begin{array}{l}E \text { (Vaccine } \\
\text { efficiency) }\end{array}$ & 0.99 & $\begin{array}{l}\text { Vaccine efficiency or vaccine take } \\
\text { for HS vaccine (Tabatabaei et al., } \\
\text { 2007) }\end{array}$ \\
\hline
\end{tabular}

\begin{tabular}{lll}
$P$ & 0.80 & $\begin{array}{l}\text { Population fraction vaccinated at } \\
\text { birth is assumed to be } 80 \% \text { of the } \\
\text { total births }\end{array}$ \\
$\begin{array}{l}\omega \text { (Rate } \\
\text { of waning } \\
\text { immunity) }\end{array}$ & $180 / 6=30$ & $\begin{array}{l}\text { Immunity of alum precipitated } \\
\text { HS vaccine is from } 4 \text { to } 6 \text { months } \\
\text { (Cockrill, 1977) }\end{array}$ \\
\hline
\end{tabular}

MATLAB and Simulink were used to create and run the model. Since, outbreaks of HS mainly occurred in the monsoon months from July to September (Gowrakkal et al., 2014), we ran our model for 90 days (3 months). With the aforementioned model parameters in Table 1 and following the posteriori model building approach by using the HS outbreak data (Mitra et al., 2013), we calculated the best possible $R_{0}$ parameter (which is equal to 1.011) by comparing the total infectious fraction of animals at the end of the outbreak for different transmission parameter $(\beta)$ values. The graph (Fig. 2) below shows our described approach.

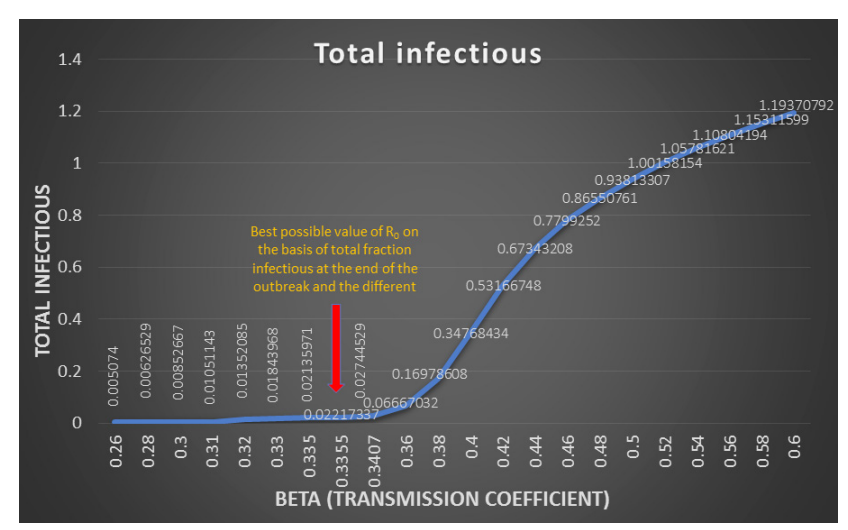

Fig. 2: Best possible $R_{0}$ value on the basis of total fraction of animals infectious at the end of the outbreak

The population of cattle and buffalo at risk was 7120 . The best possible transmission coefficient $(\beta)$ to imitate the outbreak was found to be 0.335 (Kermack and McKendrick, 1927). The efficacy of the HS vaccines in some of the experimental studies was found to be nearly 100\% (Mohammad et al., 2007). Hence, we used the vaccine efficiency $(E)=0.99$.

We used $R_{0}=-\operatorname{Ln}(1-I) / I$ formula for the calculation of the basic reproduction number for various outbreaks of HS in Kazakhstan in May, 2016 ("Promed Post - ProMED-mail," n.d.), in Israel in March, 2017 ("PRO/AH> Hemorrhagic septicemia - Israel: (HZ) bovine, OIE Outbreak Watch," 
n.d.), in Malaysia from $29^{\text {th }}$ September to $10^{\text {th }}$ October, 2003 (Bisht et al., 2004) and in Haryana state of India from 1995 to 1999 (Jindal et al., 2002), where $I$ was the proportion infected at the end of the outbreak (Dietz , 1993).

Finally, we introduced a vaccination campaign by using a constant vaccination signal in the Simulink model starting in the first week the outbreak (Mitra et al., 2013) from the 5th day to the 20th day of the outbreak with a target of $90 \%$ of the population to be covered under the vaccination campaign during this period. Hence, the per day vaccination target was $6 \%$ of the total population.

\section{RESULTS AND DISCUSSION}

The best possible transmission coefficient $(\beta)$ to imitate the outbreak was found to be 0.335 (Kermack and McKendrick, 1927). The best possible $R_{0}$ was calculated by comparing the total infectious fraction of animals at the end of the outbreak for different transmission parameter $(\beta)$ values. The best possible $R_{0}$ calculated by the posteriori model building approach by using the HS outbreak data (Mitra et al., 2013) was found to be 1.011 .

$R_{0}$ for the outbreak in bovines in Kazakhstan in May, 2016 ("Promed Post - ProMED-mail," n.d.) was found to be
1.003. $R_{0}$ for the outbreak in cattle in Israel in March, 2017 ("PRO/AH> Hemorrhagic septicemia - Israel: (HZ) bovine, OIE Outbreak Watch," n.d.) was found to be 1.116. $R_{0}$ for the outbreak in buffaloes and cattle in Malaysia from 29 $9^{\text {th }}$ September to 10th October 2003 (Bisht et al., 2004) was found to be 1.206. The Haryana state of India faced 26 HS outbreaks in buffaloes and cattle from July 1995 to June 1999 out of which 15 outbreaks occurred in winter, 6 in the rainy season and the remaining 5 occurred in the summer season (Jindal et al., 2002). The $R_{0}$ values calculated for all the Haryana outbreaks in buffaloes and cattle ranged from 1.01 to 2.96 which are presented in the table below (Table 2).

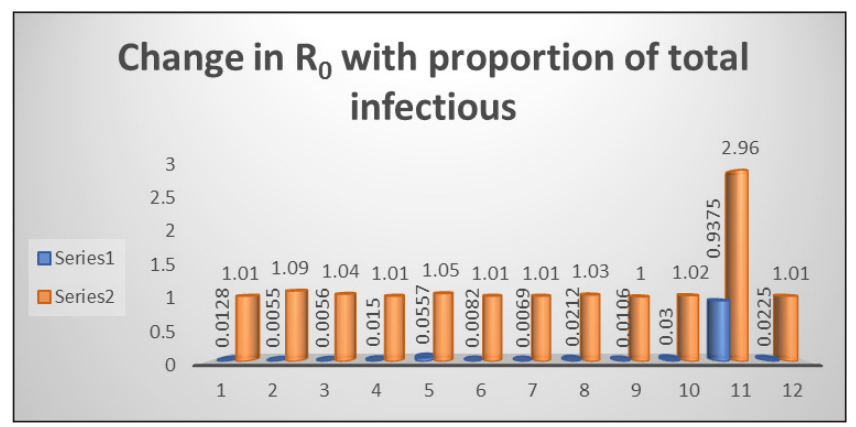

Fig. 3: Change in $R_{0}$ of HS during its outbreaks in Haryana state of India with changing proportion of total infectious animals (July 1995 to June 1999)

Table 2: $\mathrm{R}_{0}$ values calculated for all the 26 HS outbreaks from July 1995 to June 1999 in Haryana state of India

\begin{tabular}{|c|c|c|c|c|c|c|c|}
\hline \multirow[b]{2}{*}{ Year } & \multirow[b]{2}{*}{ Quarter } & \multicolumn{3}{|c|}{ Buffalo } & \multicolumn{3}{|c|}{ Cattle } \\
\hline & & $\begin{array}{l}\text { Total Susceptible } \\
\text { population }\end{array}$ & Total Infectious & $\mathbf{R}_{0}$ & $\begin{array}{l}\text { Total Susceptible } \\
\text { population }\end{array}$ & Total Infectious & $\mathbf{R}_{0}$ \\
\hline \multirow{2}{*}{1995} & Jul-Sep & 3520 & 45 & 1.01 & - & - & - \\
\hline & Oct- Dec & - & - & - & - & - & - \\
\hline \multirow{4}{*}{1996} & Jan-Mar & - & - & - & - & - & - \\
\hline & Apr-Jun & 1800 & 10 & 1.09 & - & - & - \\
\hline & Jul-Sep & 2500 & 14 & 1.04 & 190 & 24 & 1.07 \\
\hline & Oct-Dec & 2000 & 30 & 1.01 & - & - & - \\
\hline \multirow{4}{*}{1997} & Jan-Mar & 11500 & 641 & 1.05 & 350 & 20 & 1.02 \\
\hline & Apr-Jun & 5000 & 41 & 1.01 & - & - & - \\
\hline & Jul-Sep & 4800 & 33 & 1.01 & - & - & - \\
\hline & Oct-Dec & - & - & - & - & - & - \\
\hline \multirow{4}{*}{1998} & Jan-Mar & 20500 & 435 & 1.03 & - & - & - \\
\hline & Apr-Jun & 3022 & 32 & 1.00 & - & - & - \\
\hline & Jul-Sep & 2500 & 75 & 1.02 & - & - & - \\
\hline & Oct-Dec & 16 & $15^{*}$ & 2.96 & - & - & - \\
\hline \multirow{2}{*}{1999} & Jan-Mar & 2755 & 62 & 1.01 & 200 & 3 & 1.01 \\
\hline & Apr-Jun & - & - & - & - & - & - \\
\hline
\end{tabular}


During the 90-day course of the outbreak, the proportion of the susceptible animals decreased from 0.99 to 0.97 and the proportion of the infectious decreased from 0.0005 to 0.0003. 0.01 proportion of the animals recovered during this duration of the outbreak. The critical proportion of the animals to be vaccinated $\left(1-1 / R_{0}\right)$ to stop the outbreak was found to be 0.005 .

After the introduction of the vaccination campaign from the $5^{\text {th }}$ to the $20^{\text {th }}$ day of the outbreak, the proportion of the susceptible animals declined from 0.99 to 0.4 on the last day of the campaign. The proportion of the infectious declined from 0.0005 to 0 with in a time span of first 33 days of the outbreak.

The delineation of effectual control programs for HS is often impeded by the lack of the basic sero-epidemiological information. In this study of mathematical model designing for HS, we used an outbreak data from Murshidabad district, West Bengal, India (Mitra et al., 2013) to imitate the outbreak. This helped us in the better understanding of the HS disease dynamics during the outbreak and in finding the critical intervention times for vaccination of the remaining susceptible animals for better control of the outbreak. We used the parameters calculated from the outbreak data to formulate our model for HS to further predict the impact of vaccination programs on HS outbreak control. We assumed homogeneous mixing of animals for HS transmission during the outbreak.

Our results show that the $R_{0}$ calculated for the data of various HS outbreaks in Kazakhstan in May, 2016 ("Promed Post - ProMED-mail," n.d.), in Israel in March, 2017 ("PRO/AH> Hemorrhagic septicemia - Israel: (HZ) bovine, OIE Outbreak Watch," n.d.), in Malaysia from $29^{\text {th }}$ September to $10^{\text {th }}$ October, 2003 (Bisht et al., 2004), and in Haryana state of India from July 1995 to June 1999 (Jindal et al., 2002) ranged from 1.003 to 2.96. The abovecalculated lower values of $R_{0}$ for HS are may be due to the quicker treatment and vaccination interventions in its outbreaks. Hence, these small $\mathrm{R}_{0}$ values also point towards the fact that on time treatment and vaccination campaigns during the outbreaks are always beneficial for the control of this deadly disease. The disease dynamics also vary with the use of different types of HS vaccines based on the efficacy and duration of immunity provided by the vaccine and this is a matter of further research. Using the results for efficacy and duration of immunity of the HS vaccines from the vaccination studies in natural environment instead of the small experimental vaccination studies, can be more reliable. Further analysis of the contact patterns between animals can shed more light on the epidemiology and spread of HS in a specific area. More precise demographic, biological, and epidemiological information and real-time data about HS can be helpful in designing more robust and informative mathematical models for this disease. A combination of factual and theoretical research is needed for better understanding of HS and for animal health policy planning. More complex stochastic models can be used to analyze both endemic cycle and outbreak episodes of HS in endemic animal populations of India.

\section{CONCLUSION}

The success of introduction of a vaccination campaign in controlling an HS outbreak is variable if vaccination is introduced at early, mid or late phases of the outbreak. We also conclude that animal vaccination modeling for eradication of HS by mass regional or nationwide vaccination campaigns can be understood even by simpler mathematical models and these models can be useful in assessing alternate strategies for control of HS and furthermore, in guiding HS related epidemiological research.

\section{REFERENCES}

Abusalab, M., Ahmed, A.M. and Hamid, M.E. 2003. Haemorrhagic Septicaemia: A General Review. The Sudan J. Vet. Res., 18: 1 -14.

Bisht, K.S., Hassan, L., Saharee, A.A., Zunita, Z. and Nadzri, S. 2004. Outbreak investigation of haemorrhagic septicaemia in buffalo and cattle in Perak, Malaysia. Anim. Heal. a Break. Econ. Dev. 11th Int. Conf. Assoc. Institutions Trop. Vet. Med. 16th Vet. Assoc. Malaysia Congr. 23-27 August 2004, Petaling Jaya, Malaysia, pp. 263-265.

Cockrill, W.R. 1977. The Water Buffalo. Rome: Animal Production and Health Series No. 4. Food and Agriculture Organization of the United Nations.

Dietz, K. 1993. The estimation of the basic reproduction number for infectious diseases. Stat Methods Med. Res., 2(1): 23-41.

Dutta, J., Rathore, B.S., Mullick, S.G., Singh, R. and Sharma, G.C. 1990. Epidemiological studies on the occurrence of haemorrhagic septicaemia in India. Indian Vet. J., 67(10): 893-899. 
Farooq, U., Saeed, Z., Khan, M.A., Ali, I. and Qamar, F. 2011. Sero-surveillance of hemorrhagic septicemia in buffaloes and cattle in Southern Punjab, Pakistan. Pak. Vet. J., 8318(3): 2074-7764.

Gajendragad, M.R. and Uma, S. 2012. Haemorrhagic Septicaemia in India. Project Directorate on Animal Disease Monitoring and Surveillance, Bengaluru, Karnataka. (http:// www.nadres.res.in).

Gowrakkal, M., Chandrashekar, M., Bhajantri, S., Satav, J., Chandakala, G., Mayanna, A., Byregowda, S. and Renukaprasad, C. 2014. Evaluation of immuno efficiency of hemorrhagic septicemia vaccine strain (vaccine seed). Asian Pac. J. Trop. Biomed., 4(1): 263-267.

PromedPost-ProMED-mail[WWWDocument],n.d.URLhttps:// promedmail.org/promed-post/?id=20160513.4218967 (accessed 1.8.20).

PRO/AH> Hemorrhagic septicemia - Israel: (HZ) bovine, OIE $\sim$ Outbreak Watch [WWW Document], n.d. URL https:// outbreakwatch.blogspot.com/2017/03/proah-hemorrhagicsepticemia-israel-hz.html?m=0 (accessed 1.8.20).

ICAR-NIVEDI. 2018. All India coordinated research project on animal disease monitoring and surveillance (AICRP on ADMAS) annual report. Bangalore.

Jindal, N., Kumar, S., Narang, G., Chaturvedi, G.C., Tomar, P. and Garg, D.N. 2002. Some Epidemiological observations on Haemorrhagic Septicaemia in Buffaloes and Cattle in Haryana State of India. Buffalo J., 2: 273-280.

Kermack, W.O. and McKendrick, A.G. 1927. A Contribution to the Mathematical Theory of Epidemics. Proc. R. Soc. A Math. Phys. Eng. Sci., 115: 700-721.
Kumar, A.A., Harbola, P.C., Rimler, R.B. and Kumar, P.N. 1996. Studies on Pasteurella multocida isolates of animal and avian origin from India. Ind. J. Comp. Microbiol. Immunol. Infect. Dis., 17(2): 120-124.

Mitra, J., Chowdhury, M. and Bhattacharya, C. 2013. Outbreak of Hemorrhagic Septicemia in free range buffalo and cattle grazing at riverside grassland in Murshidabad district, West Bengal, India. Explor Anim. Med. Res., 3(2): 178-182.

Schrer, A. and McLean, A. 2002. Mathematical models of vaccination. British Med. Bull., 62(1): 187-199.

Shah, Najmul H., Shah, Nasir H. and Graaf, F.K. 2006. Protection against haemorrhagic septicaemia induced by vaccination of buffalo calves with an improved oil adjuvant vaccine. FEMS Microbiol. Lett., 155: 203-207.

Shome, R., Deka, R.P., Sahay, S., Grace, D. and Lindahl, J.F. 2019. Seroprevalence of hemorrhagic septicemia in dairy cows in Assam. India. Infect. Ecol. Epidemiol, 9: 1604064.

Singh, B., Prasad, S., Verma, M.R. and Sinha, D.K. 2014. Estimation of Economic Losses due to Haemorrhagic Septicaemia in Cattle and Buffaloes in India. Agric. Econ. Res. Rev., 27: 271

Tabatabaei, M., Moazzeni Jula, G.R., Jabbari, A.R. and Esmailzadeh, M. 2007. Vaccine efficacy in cattle against hemorrhagic septicemia with live attenuated aroA mutant of Pasteurella multocida B:2 strain. J. Cell Anim. Biol., 1: $62-065$

Verma, R. and Jaiswal, T.N. 1998. Haemorrhagic septicaemia vaccines. Vaccine, 16(11-12): 1184-1192.

Woolhouse, M.E.J., Haydon, D.T. and Bundy, D.A.P. 1997. The Design of Veterinary Vaccination Programmes. Vet. J., 153(1): 41-47. 